American Journal of Applied Sciences 8 (12): 1302-1306, 2011

ISSN 1546-9239

(C) 2011 Science Publications

\title{
Contemporary Sculptures: Decoding the Body of Aesthetic Knowledge Suitable for Public Parks
}

\author{
Adool Booncham, Songkoon Chantachon and Sastra Lao-Akka \\ Research Institute of Northeastern Art and Culture, \\ Mahasarakham University, Maha Sarakham, Thailand
}

\begin{abstract}
Problem statement: The contemporary sculptures are constructions in public parks for people to use and appreciate. These are new things which Thai society has just known. The knowledge and understanding of the matter as mentioned are still in the limited circle. However, there is a lack of research study to seek the body of aesthetic knowledge suitable for constructing sculptures in the public park in Thailand. The purpose of this research was to examine the background, current condition, problem and decoding the body of aesthetic knowledge of contemporary sculptures suitable for public parks in Thailand. Approach: The research area covered Bangkok, Chiang Mai, Phuket, Songkhla and Ubon Ratchathani provinces in which there are constructions of contemporary sculpture permanently installed in the public parks. The research procedure used the qualitative research methodology. Data were collected from related literature and field studies using survey, interviews and focus group discussion from a group of totally 203 informants. The findings were presented by means of a descriptive analysis. Results: There are constructions of contemporary sculptures permanently installed in 15 parks with totally 101 pieces in Thailand. Saphan Hin Park in Phuket is the first place where there was a construction of a contemporary sculpture in 1969. In Bangkok there were 8 parks with totally 40 pieces of sculpture. In Chiang Mai there were 2 parks with 43 pieces. In Phuket there were 2 parks with 2 pieces. In Songkhla there were 2 parks with 15 pieces. And in Ubon Ratchathani there was 1 park with 1 piece of sculpture. At present it has been found that there are 98 contemporary sculptures in all the public parks. In Bangkok there are 39 pieces. In Lanna King Rama IX Park, Chiang Mai, 1 piece was stolen and 1 piece is not at the point of installation. In Saphan Hin Park, Phuket, the area has been adjusted to be the grass lawn. However, the sculptures in the other parks are in complete conditions and are well cared. The problems found generated from a lack of linking data concerning the background, importance and care-taking, causing a lack of understanding the matters as mentioned. Also, there were problems of sculpture's forms which are abstract art as personal characteristics of artists. There is appreciate, causing people to be unable to appreciate the aesthetics as they should. There were 3 aspects of aesthetics of the contemporary sculptures in the public parks: contents with subject matters which could mediate beauty, the way of life and local culture as things which everyone could appreciate and understand; semi-abstract art sculpture's form which people could appreciate the aesthetics more easily than the abstract art and the use of the form expressing the beauty of different visual elements which could respond to the content and environment and in the environment, there were designs and adjustments of the environment to suit and relate to the sculpture and activities of the people who used the services and to enhance to generate aesthetics of sculptures and environment. Conclusion: The aesthetics of the contemporary sculptures in the public parks consists of 3 aspects: content, sculpture's form and environment to be relate to activities of the people who use services in the public parks to be able to appreciate aesthetics of the sculptures completely.
\end{abstract}

Key words: Contemporary sculpture, public parks, appreciate aesthetics, aesthetic knowledge, descriptive analysis, deeply tied, education provision, media involving, connecting matters

Corresponding Author: Adool Booncham, Research Institute of Northeastern Art and Culture, Mahasarakham University, Maha Sarakham, Thailand 


\section{INTRODUCTION}

Sculpture is a branch of fine arts which humans create for appreciation in aesthetic values. There are expressions of sensitive emotions and an important role in connecting matters, beliefs, thoughts and feelings of humans. Also, it is one thing which expresses cultural advancements of mankind. Thai society has been deeply tied to sculptures as ideal media involving beliefs and religions which have been constructed by people or kings. Contemporary sculptures in Thailand have been generated from education provision based on the western art academic paradigm, Professor Silpa Bhirasri [1892-1962] was the founder. Later, Later, the form has been developed, leading to abstract art and non-objective art which are different from Thai traditional popularism. Also, there are constructions in public parks for people to appreciate aesthetics of the sculptures and environment. There occur feelings of relaxation and pleasure to see beautiful things. It is the uses of sculptures for mental benefits, regarded as constructions of contemporary sculptures and the environment as public areas which everyone can come to use and appreciate. These are new things which Thai society has just known and it is a new word not yet wellknown. The knowledge and understanding of the matter as mentioned are still in the limited circle. Some artists are already aged and some passed away. Some pieces of contemporary sculpture lost and decayed. However, there is a lack of research study to seek the body of aesthetic knowledge suitable for constructing sculptures in the public park in Thailand.

\section{MATERIALS AND METHODS}

The qualitative research methodology was used. Data were collected from related literature and field studies. The research was conducted using a primary survey form, a non-structured interview form and focus group discussion with a group of totally 203 informants. They included: a group of 13 experts in sculpture, a group of 40 sculptors area care-takers and a group of 150 park service users. The collected data were checked for correctness and completeness using the methodological triangulation technique. The research findings were checked by experts in visual arts and subsequently presented by means of a descriptive analysis.

\section{RESULTS}

The background of constructing contemporary sculptures in the public parks of Thailand: In Thailand there were constructions of contemporary sculptures permanently installed in 15 parks in 5 provinces. In
Bangkok in 5 parks: Chatuchak Park had 6 pieces of work, 5 pieces were constructed according to The 2 nd ASEAN Sculpture Symposium Project in 1983; and later, 1 additional piece was constructed in 1987. Thonburirom Park had 1 piece of work, constructed in 2009 according to The Sculpture Installation Project in Cooperation between Bangkok Metropolitan Administration and Silpakorn University. Benchakitti Park had 1 piece of work, constructed in 1994 in Commemoration of H.M. Queen Sirikit's 60th Birthday. Bangkok Forest Park in Commemoration had 1 piece of work, constructed in 2009 according to the sculpture installation project in the same way as Thonburirom Park. Forest park in commemoration at the foot of the great king taksin bridge [on Thoburi bank] had 2 pieces of work, constructed in 2009 according to The Sculpture Installation Project in the same way as Thonburirom Park. Lumphini Park had 8 pieces of work from 5 times of constructions: First time in 1985 from The Youth for Sculptural Works Project according to the slogan of International Youth Year, with 1 piece of work; second time during 1991-1994 from The Youth for Sculptural works Project under the meaning involving nature and environmental conservation, with 3 pieces of work; third time in 2007 on the occasion of the 30th year of Dichan Magazine, with 1 piece of work; fourth time in 2008 on the occasion of the 80th Birthday of H.M. King Bhumibol Adulyadej the Great and the 120th year of ThaiJapanese diplomatice relationship, with 1 piece of work ; and fifth time in 2009 the construction according to The Sculpture Installation Project in the same way as Thonburirom Park, with 1 piece of work. Wachirabenchatat Park had 3 pieces of work from 2 times of constructions: first time in 2006 from The CPAC Dsign 4 Parks Project, with 1 piece of work; and second time in 2009 according to The Sculpture Installation Project in the same way as Thonburirom Park, with 2 pieces of work. And Benchasiri Park had 18 pieces of work. The constructions could be divided into 3 parts: Part 1 in 1992, the sculptures were selected from master pieces of famous sculptors in commemoration of H.M. Queen Sirikit's 60th Birthday, with 11 pieces of work. Part 2 during 1992-1997 from The Youth for Sculptural Works Project in Commemoration of H.M. Queen Sirikit's 60th Birthday, with 6 pieces of work. And Part 3 in 2006 from The CPAC Dsign 4 Parks Project, with 1 piece of work. In Chiang Mai there were 2 parks: Lanna King Rama IX Park had 42 pieces of work. The construction were divided into 3 groups: Group 1 during 1990-1995 from the youth for sculptural works project in lanna king rama ix park had 11 pieces of work. 
Am. J. Applied Sci., 8 (12): 1302-1306, 2011

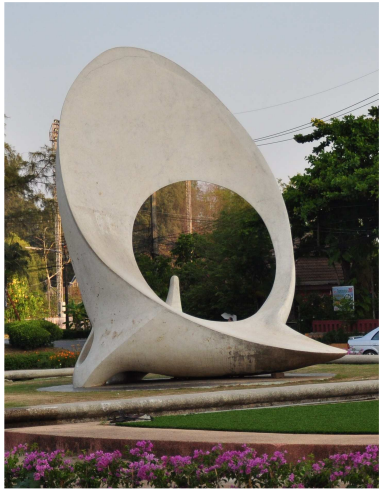

Fig. 1: Chaovalit Hatsaphong, 1969. The milestone, concrete, hight $600 \mathrm{~cm}$. Saphan hin park, Phuket

Group 2 during 1994-1995 had 22 pieces of work of carved sandstone sculpture and group 3 in 1997 from The Youth for Sculptural Works Project in Lanna King Rama IX Park in Commemoration of H.M.King Bhumibol Adulyadej's 72nd Birthday had 9 pieces of work. And Buak Hard Public Park had 1 piece of work, constructed in 2005 according to The Sculpture Contest Project installed in Chiang Mai province. In Phuket there were 2 parks: Public Park in Commemoration 100th Years had 1 piece of work, constructed during 2005-2006 for being memorial of Tsunami disaster. Saphan Hin Park was the first place of Thailand where the contemporary sculpture was constructed and permanently installed in 1969, with 1 piece of work was shown in Fig. 1, in remembrance of Captain Edward Thomas Miles [1849-1944]. Captain Miles was the man who took the first mineral-digging boat of the world to dig tin in Thung Kha Gulf for the first time of the world. Songkhla had 2 parks: Sculpture Park in Commemoration of H.R.H. Princess Maha Chakri Sirindhorn's 50th Birthday had 14 pieces of work, constructed in 2005 according to The International of Symposium of Monumental Sculpture in Celebration on the Auspicious Occasion of H.R.H. Princess Maha Chakri Sirindhorn's 50th Anniversary. Seri 1943 Park had 1 piece of work, constructed in 2008 according to The 1st International Contemporary Sculpture Project. Ubon Ratchathani province had 1 park, Thung $\mathrm{Si}$ Muang Park, with 1 piece of work, constructed in 1995 under The Youth for Sculptural Works Project.

Current conditions and problems of contemporary sculpture in the public park of thailand: Currently, 39 pieces of contemporary sculpture appear in the public parks of Bangkok. One piece of work in Lumphini Park disappeared.

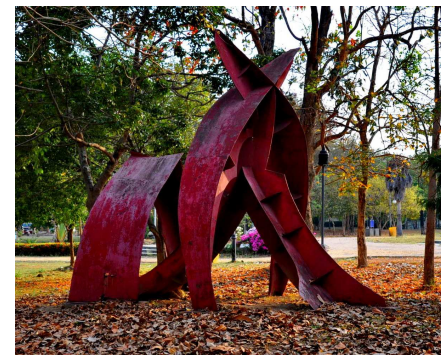

Fig. 2: Chanvit Yeamprapha, 1990. Red structure, iron, hight $350 \mathrm{~cm}$. Lanna King Rama IX park, Chiang Mai

One component of one piece of work of the sculpture from the CPAC Dsign 4 Parks Project in Wachirabenchatat Park is broken and it has been left outside the area of the sculpture installation. In Lanna King Rama IX Park, Chiang Mai, there is a lack of good care-taking due to the problem of hiring a private company to improve the landscape. In addition, one piece of sculpture was stolen, one piece of work was taken out of the point of installation, one piece of work made of iron was shown in Fig. 2 and one piece of sculpture made of wood are in the state of much erosion. Also, the area conditions have been left wild with plants. For Saphan Hin Park in Phuket, the area around the sculpture has been adjusted from the fountain pond to be the grass lawn, enabling people to come to appreciate the piece of work. As for the sculptures in the other public parks are in complete conditions and are well taken care. In terms of subject matters mediating goodness, beauty of nature and local culture. The sculpture's forms as abstract art and semiabstract art express beauty of the form though different visual elements. In term of the environments around the piece of work, there are adjustments and decorations for enhancing aesthetics of the sculptures and environments. It is an exception for Lanna King Rama IX Park, Chiang Mai, that the condition is full of wild plants. Aesthetics of the sculptures can also decrease. The people who use the public parks opine that it is a good thing to have constructions of contemporary sculptures in the public parks. However, they hardly understand the matters and the sculpture's form. The problems of contemporary sculptures generate from the lack of clear understanding about the methods of taking care of the sculptures and a lack of connecting different information concerning construction, importance and care-taking, causing them to lack understanding of the matters as mentioned. It also includes the problem of the sculpture's form which is abstract art with personal characteristics of each artist. Also, there is not any information media for people to appreciate the purposes and forms of the sculpture, causing them not to be able to appreciate aesthetics as they should. 
The body of aesthetic knowledge of contemporary sculptures suitable for public parks in thailand: Aesthetics of contemporary sculptures in the public parks consists of 3 aspects.

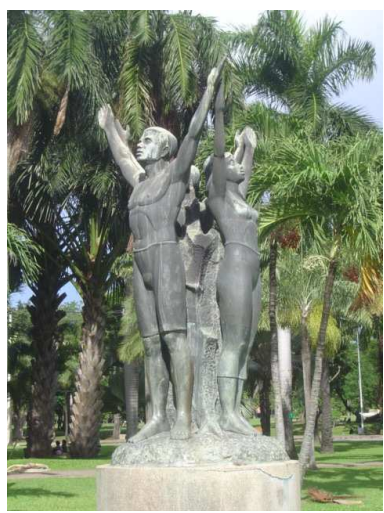

Fig. 3: Chakaphan Vilasinikul, 1985. Participation development and peace, bronze, hight $250 \mathrm{~cm}$. Lumphini park, Bangkok

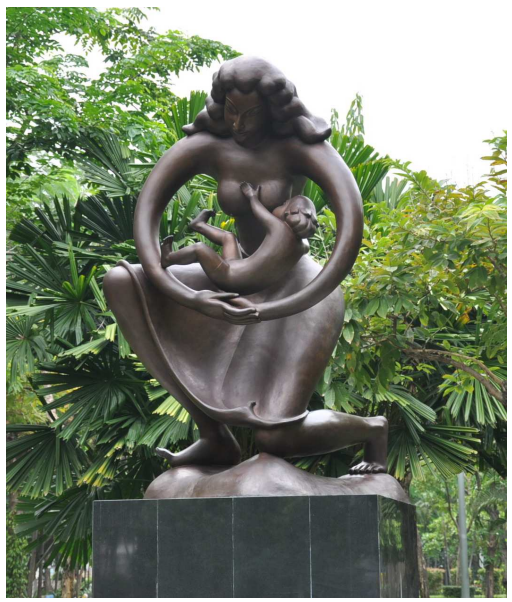

Fig. 4: Khien Yimsiri, 2009. Protector, bronze, hight $395 \mathrm{~cm}$. Forest park in commemoration at the foot of the great king Taksin bridge [on Thonburi bank], Bangkok

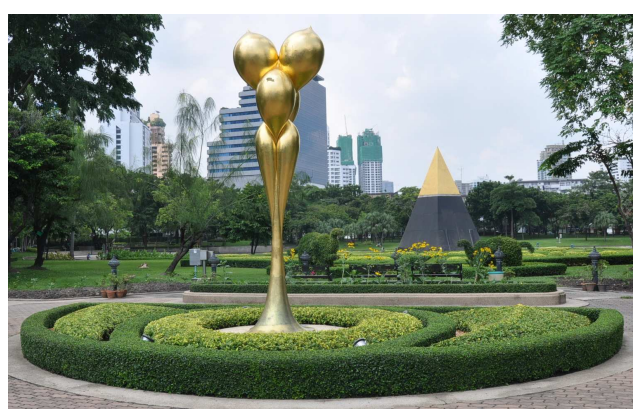

Fig. 5: Nonthiwat Chandhanaphalin, 1992. Growth, bronze, hight $400 \mathrm{~cm}$. Benchasiri park, Bangkok
Lowell et al. (2009) the aspect of content has subject matters which mediate goodness, love, unity, philosophy of life, human intention, beauty of nature, the way of life and local culture. It is the matter which everyone can perceive and understand, not the artist's personal matter; such as the sculpture title "Participation Development and Peace" shown the content to unite collaborate on the development of young people seeking peace and unity in the development of human peace and happiness. The sculpture was shown in Fig. 3.

Awomeso et al. (2010) the aspect of the form; In the aspect of semi-abstract art sculpture's form, people will more easily appreciate aesthetics than abstract art. The uses of simple and uncomplicated forms using the principle for arts composition in order for the form to have uniqueness: can show beauty of the form, mass, plans, lines, texture, materials and colors which can respond to the contents and environments. Furthermore, aesthetics of the sculptures still depends on good conditions as generated from caretaking; such as the sculpture title "Protector" shown the form as the love of man to child, in the gesture of carrying child in her arms, to handle curve fully, no pains. Protector is as form as a woman that replace by the curve-lines that means love of mom to her child. The sculpture was shown in Fig. 4.

Yee and San (2011) the aspect of the environment consists of design and adjusting and decorating the environment to be appropriate, to relate to the sculptures and activities of the people who come to use services in each local area, enhancing to generate aesthetics of the sculptures and environments. There must be beautiful visions and good caretaking for people to be able around them and to generate pleasure and joy to see aesthetic things; such as the sculpture was constructed and permanently installed in Benchasiri Park, Bangkok. That is planned to design the park and installed the contemporary sculpture, the various elements of the park along with the construction of the park. The contemporary sculpture and environment of the park is harmony. The park maintenance department is also responsible for maintaining a beautiful garden in the state do. The contemporary sculpture has an aesthetic result more. That was shown in Fig. 5.

\section{DISCUSSION}

Contemporary sculptures in the public parks are constructions of the sculptures in the open air or they are installed in the open areas outside the buildings which people of all genders and all ages use services. There are convenient interactions and appreciation. The sculptures of this type will provide more values of 
natural feelings than the pieces of work installed in the museum with a narrow and airless area. Good sculptural works, if presented in an inappropriate climate, will also derease their values and beauty (Lowell et al., 2009). The sculptures of this type occur in large cities where living conditions are rather confused. One method to help them relax is taking art aesthetics to share operation with such environments (Awomeso et al., 2010). Contemporary sculptures have been created in abstract art and non-objective art styles, they still beneficial to communicate with no less meanings and feelings than the traditional popular style because the contemporary sculptures still have contents which artists want to transfer to visitors to appreciate such as love, holding and protecting mother's baby and so on. Contents are greatly important compositions of art besides forms, materials, processes and technique of presentations to generate appreciation and joyful pleasure to see beautiful things. It is the use of sculpture to generate mental benefits. The sculptures are art media related to the society, generated from that every artist is a member of the society, who has higher aesthetic gifts or special abilities than any other people. Artists usually can express aesthetic emotions into art works which society member who have common emotions can perceive and appreciate and support further creation. They show satisfaction and pleasure in the way of life to live together. Therefore, sculptures are useful to respond to the needs of the society. People have happiness in life with common aesthetic emotions. The society which cooperatively perceives and promotes artists to create sculptural works until they become properties and heritages of that society, which may be longer than the lives of creators and consumers of the pieces of work in the contemporary period (Yee and San, 2011).

\section{CONCLUSION}

This research aimed to examine the background, current conditions and problems and to seek the body of aesthetic knowledge of contemporary sculptures suitable for the public parks in Thailand, specifically in Bangkok, Chiang Mai, Phuket, Songkhla and Ubon Ratchathani provinces. These 5 provinces were the area with constructions of contemporary sculptures permanently installed in the public parks during different periods of time and on different occasions for more than 40 years. The contemporary sculptures were in semi-abstract art and abstract art style. The aesthetics of the contemporary sculptures in the public parks consists of 3 aspects: content, sculpture's form and environment to be relate to activities of the people who use services in the public parks to be able to appreciate aesthetics of the sculptures completely.

\section{ACKNOWLEDGEMENT}

My sincere thanks go to The commission on higher education for providing a scholarship according to The Strategic Scholarships Fellowships Frontier Research Networks in 2008. This dissertation received a sponsorship for the fiscal year 2010 from Mahasarakham University and The Research Institute of Northeastern Art and culture, mahasarakham university.

\section{REFERENCES}

Awomeso, J.A., A.M. Taiwo, A.M. Gbadebo and A.O. Arimoro, 2010. Waste disposal and pollution management in urban areas: A workable remedy for the environment in developing countries. Am. J. Environ. Sci., 6: 26-32. DOI: 10.3844/ajessp.2010.26.32

Lowell, C., D. Jordan and Y. Liang, 2009. Management policy in and typology of state park systems. Am. J. Environ. Sci., 5: 187-196. DOI: 10.3844/ajessp.2009.187.196

Yee, J. and C.N. San, 2011. Consumers' perceived quality, perceived value and perceived risk towards purchase decision on automobile. Am. J. Econ. Bus. Admin., 3: 47-57. DOI: 10.3844/ajebasp.2011.47.57 